\title{
CONCEPTOS DE PSICOLOGÍA
}

Fermín Zumano Hernández* cecilz83@hotmail.com.

García Cadena Cirilo, et al. (comp.) Trillas, 2008

El texto presenta un panorama de la psicología actual. El libro muestra tendencias innovadoras de la psicología contemporánea como la "psicología ambiental " $\mathrm{y}$, al mismo tiempo, se realiza un balance de posturas psicológicas ya consolidadas y maduras como la psicología clínica y la psicología de la memoria. Asimismo se presentan los avances de la psicología de las emociones de larga tradición filosófica.

Desde el punto de vista didáctico el texto presenta ventajas y desventajas. La ventaja evidente es la posibilidad de presentar una visión panorámica de la psicología contemporánea. Otras dos ventajas son la claridad del lenguaje en la exposición de una disciplina, cada vez más técnica, y la posibilidad de recurrir a una bibliografía especializada y actualizada indispensable para alumnos que están por terminar los créditos de su licenciatura y que se dispongan a enfrentar la redacción de su tesis. Estas dos ventajas son suficientes para incluir el libro como texto base de un curso o como bibliografía complementaria. En cuanto a la desventaja, lo principal que observamos es la enorme cantidad de términos especializados que se presentan como parte de los argumentos y que no se definen.

Desde el punto de vista del contenido, lo primero que nos parece debe ser advertido, es la falta de desarrollo del trasfondo epistemológico que corre a lo largo de todas las propuestas presentadas. En efecto, la diversidad presentada en las tendencias psicológicas actuales se debe a los ajustes y amalgamas epistemológicos que subyacen a todo movimiento de los nuevos planteamientos en el discurso científico.

En cuanto al contenido dedicado a la psicología clínica se destaca, en primer lugar la crítica al equívoco común según el cual, el psicoanálisis equivale a toda la psicología clínica. Este equívoco, como se sabe, ha llevado al error de suponer insuficientes otras propuestas de la psicología clínica como la Gestalt, la psicología cognitivo conductual, humanística o sistémica.

En cuanto a psicología ambiental, es muy interesante la propuesta epistémica según la cual no se trata de trabajar psicológicamente con la tolerancia de la diversidad ambiental, sino que de lo que se trata es de establecer los mecanismos adecuados para apreciar lúdicamente esta diversidad. El punto fundamental consiste en fracturar la visión natura- lista de la naturaleza, generada por siglos en los cuales la concepción científicofísica predominado. No se trata ya de ver en la naturaleza un objeto de manipulación tecnológica, sino establecer las bases psicológicas para ampliar la relación de la psique con la naturaleza en un grado de simbiosis cada vez más alto. 
Creo que uno de los conceptos más innovadores de la psicología de la memoria es la noción de redes de significación, en los cuales descansa la lógica de nuestra capacidad cognitiva de asimilar conocimiento. El concepto trata de captar la complejidad del conocimiento humano y los mecanismos de su evolución. Lo que se puede concluir de este concepto es la necesidad hermenéutica de interpretar los vericuetos de la significación que subyacen en el proceso más simple del conocimiento. 